\title{
Antigen based detection of cystic echinococcosis in buffaloes using ELISA and Dot-EIA
}

\author{
A. Sangaran ${ }^{1} \cdot$ S. T. Bino Sundar ${ }^{1} \cdot$ Bhaskaran Ravi Latha $^{1}$
}

Received: 26 March 2015/Accepted: 8 March 2016/Published online: 4 April 2016 (C) Indian Society for Parasitology 2016

\begin{abstract}
Cystic echinococcosis is caused by the larval stage of the dog tapeworm, Echinococcus granulosus. The disease is recognized as one of the world's major zoonoses affecting human beings and domestic animals apart from its economic and public health importance. Development of the cysts in the intermediate host such as buffaloes
\end{abstract} occurs in the lungs, liver and other organs. In this stur detection of circulating antigen in the diagnosis of cysti echinococcosis in buffaloes was done using enzym linked immunosorbent assay and Dot-Enzyme imm . osay (Dot-EIA). The sensitivity and specificity we detern as 89 and $92 \%$ respectively, whereas th os $f$ Dot-EIA were determined as 94 and $96 \%$.

Keywords Cystic echinococcosis . uffaloes.

Antigen detection - ELISA · Dot-EIA

\section{Introduction}

Cystic echinocor cosis, a oonotic disease of man and animals is cau ea the larval stage (metacestodes) of the dog cestod Echin ccus granulosus, the life cycle involvin two mammalian hosts. Definitive hosts are dogs in whose estin the adult worms occur. Intermediate hos o her ores and omnivores wherein the developto zysts occurs in liver, lungs and other organs. Acc ntal infection of man occurs during natural

\section{S. T. Bino Sundar}

drbinosundar@yahoo.co.in

1 Department of Veterinary Parasitology, Madras Veterinary College, Tamilnadu Veterinary and Animal Sciences University, Chennai 600 007, India transmissi of marasite between the canid definitive hosts and do stic livestock intermediate hosts. In the middl ast, the jevalence of cystic echinococcosis is high in man (E ntaseb 1984) and in sheep, goats, cattle and camels (Al Yaman et al. 1985). Irrespective of the host species irfected, cysts occur mostly in liver and lungs with ying degrees of involvement of one or other of these or ans (Schantz 1972). The disease remains asymptomatic A many cases and in livestock intermediate hosts like buffaloes, the cysts are seen only on post mortem. Immunodiagnostic tests for cystic echinococcosis rely on the detection of serum antibodies and vary in their sensitivity and specificity with false negatives (Craig and Rickard 1981). To overcome such problem, the detection of circulating antigen rather than antibodies could be very useful in the immunodiagnosis of cystic echinococcosis particularly if circulating antigen is present in the false negatives (Craig and Nelson 1984). Hence, in the present study, detection of antigen in the diagnosis of cystic echinococcosis in buffaloes using ELISA and Dot-EIA was carried out to find out the sensitivity and specificity of these two assays.

\section{Materials and methods}

\section{Sera from buffaloes}

Blood samples were collected from buffaloes at the time of slaughter at the rate of $10 \mathrm{ml}$ blood per buffalo in $30 \mathrm{ml}$ test tubes and allowed to clot. The blood samples were refrigerated overnight and the sera separated, centrifuged at $2000 \mathrm{rpm}$ for $15 \mathrm{~min}$. The clean sera was pipetted into sterile $5 \mathrm{ml}$ plastic vials, preserved by adding merthiolate 
solution to a final concentration of 1:10,000 and stored at $-20{ }^{\circ} \mathrm{C}$.

\section{Preparation of hydatid fluid antigen (HFA)}

Hydatid cysts were collected from sheep and buffaloes from the slaughter house at the time of slaughter. Cysts were brought to the laboratory immediately and were washed with sterile normal saline. The hydatid fluid from the clean cysts was aspirated using a $20 \mathrm{ml}$ glass syringe, transferred into a glass container and allowed to stand for few hours. The hydatid fluid was examined microscopically to ascertain the presence (fertile) or absence (sterile) of scolices so as to assess the fertility status of the cysts. The supernatant fluid fluid from the fertile cyst was carefully aspirated and dialysed in dialysis membrane bag against Polyethylene glycol 6000 (Carbowax) for $1 \mathrm{~h}$ to concentrate the fluid to half of its original volume. The dialysed HFA was stored in $5 \mathrm{ml}$ quantities in $10 \mathrm{ml}$ sterile plastic screw cap vials with merthiolate at 1:10,000 concentration as preservative at $-20{ }^{\circ} \mathrm{C}$.

\section{Estimation of protein content of the hydatid fluid antigen}

The protein content of the dialysed hydatid fluid antige. was estimated by the method of Lowry et al. (195 ).

\section{Raising of hyperimmune serum}

Three healthy rabbits were hyperimm nised $/$ three intramuscular injections of $2 \mathrm{ml}$ of lalysed hydatid fluid antigen with Freund's adjuvant (Sign USA) it an interval of 14 days. The first injection of DF. gen was with Freund's Complete Adjuvant and the second and third injections were given wit/1 Ereund's Incomplete Adjuvant (FIA). The robl. were sked by cardiac puncture 8-10 days after the on. About $5 \mathrm{ml}$ of blood was collected from each hbit and hyperimmune serum was separated c rifuged at $3000 \mathrm{rpm}$ for $15 \mathrm{~min}$, preserved with merthio, solution in $2 \mathrm{ml}$ aliquots in $5 \mathrm{ml}$ sterile pl stic screw cap vials and stored frozen at $-20^{\circ} \mathrm{C}$.

\section{En link immunosorbent assay (ELISA)}

ELl recommended by Judson et al. (1985) for detection of circ,alating antigen was followed with modifications. The polystyrene 96 well flat bottom plates were coated with hyperimmune serum raised in rabbits against dialyzed hydatid fluid antigen at a dilution of 1:100. Before addition of the test sera, the wells in the ELISA plate were blocked with $1 \%$ Bovine serum albumin and incubated for $1 \mathrm{~h}$ at $37{ }^{\circ} \mathrm{C}$. Test sera from buffaloes were used at a dilution of
1:100 in duplicate. The plates were incubated at $37{ }^{\circ} \mathrm{C}$ for $1 \mathrm{~h}$. Known human anti-hydatid serum at a dilution of 1:100 was used to detect the circulating antigen. At the end of $1 \mathrm{~h}$ incubation, after each step, anti-human HRP conjugate was used at a dilution of 1:8000. Each plate had two HRP and one control well. The plates were incubated at $37{ }^{\circ} \mathrm{C}$ for $1 \mathrm{~h}$. After the period of incubation the substrate solution (ABTS) prepared with sodium te buf er $(\mathrm{pH}$ 4.2) and hydrogen peroxide was immedial dispensed into each well in $100 \mu \mathrm{l}$ volume us g a octapivette. After addition of substrate, the plates we incul ated at room temperature for $20-30 \mathrm{~min}$ or develo ment of colour reaction. At the end of this 1 riod, $100 \mu$ of hydrofluoric acid was added and th pla read in an ELISA reader at $405 \mathrm{~nm}$. I thi ssay, any absorbance value which was twice above absorbance value of the negative serum nas a idered as positive.

\section{Dot-Enzy im (Dot-EIA)}

The a was car ried out as per the method of Romia et al. (1992) for w ection of circulating hydatid antigens with certain nodifications. Dot-Enzyme Immunoassay (DotEIA) of collected serum samples from buffaloes was permed using the hyperimmune serum raised in rabbits ag inst dialysed hydatid fluid antigen. Nitrocellulose nembrane $(\mathrm{NCM})$ was cut into $5 \times 10 \mathrm{~cm}$ sizes for testing the sera samples from buffaloes. Rough squares were made on the NCM with each square numbered and coated with hyperimmune serum at a dilution of 1:100 in $1 \mu$ l volume. The unsaturated sites were blocked by immersing the NCM in $5 \%$ dried milk powder and incubated at $37{ }^{\circ} \mathrm{C}$ for $1 \mathrm{~h}$. Test sera from buffaloes were used at 1:100 dilution and incubated for $1 \mathrm{~h}$ at $37^{\circ} \mathrm{C}$. Human antihydatid serum was used in $1 \mu \mathrm{l}$ volume at 1:100 dilution. The NCM was then incubated in 1:8000 anti-human IgG-HRP conjugate for $1 \mathrm{~h}$. Following this the substrate solution diaminobenzidine was added for development of reaction in positive samples. In this assay, an appearance of brown dot at the site of application of the sample was considered positive.

\section{Results}

In the present study, for detection of circulating antigen for cystic echinococcosis, blood samples from 200 buffaloes (85 samples from hydatid positive buffaloes confirmed on slaughter and 115 samples from buffaloes without visible hydatid cysts) were collected at the time of slaughter and the sera separated for use in ELISA and Dot-EIA. The assays were performed using hyperimmune serum raised in rabbits against dialysed hydatid fluid antigen. 
A total of 64 hydatid cysts were collected from sheep. Out of these, 35 cysts were found to be fertile showing a fertile cyst percentage of $54.7 \%$.

The protein content of the dialysed fertile hydatid cyst fluid from sheep and buffaloes was found to be 14 and $9 \mathrm{mg} / \mathrm{ml}$ of dialysed fertile hydatid cyst fluid respectively. Gatne et al. (1990) estimated the protein content of hydatid fluid and observed the protein content ranged from 16 to $20 \mathrm{mg} / \mathrm{ml}$ of the fluid.

Seventy six buffaloes were detected positive out of 85 sera samples from hydatid positive buffaloes using hyperimmune serum against dialysed hydatid fluid antigen by ELISA. From 115 sera samples from buffaloes without any visible hydatid cysts, 9 sera samples were detected false positive. By ELISA, the sensitivity and specificity of the assay in detecting antigen for cystic echinococcosis were determined as 89 and $92 \%$, respectively.

By Dot-EIA, 80 of the 85 sera samples from buffaloes with hydatid cysts proved positive. Four sera samples from 115 buffaloes with no visible hydatid cysts were detected false positive using the hyperimmune serum against dialysed hydatid fluid antigen. A sensitivity of $94 \%$ and a specificity of $96 \%$ were observed in Dot-EIA in detecting antigen in the diagnosis of cystic echinococcosis.

\section{Discussion}

Serological tests have been reported to be very use antemortem diagnosis of cystic echinoc co is in food animals such as sheep, goats, cattle, buft loes et The use of serological tests helps to diagnose the condition before death of the animal and diagnosis of vstic echinococcosis is usually done during post mortem. $\quad$ hydatid cyst fluid as antigen in serological d. is depends mainly on the presence of protein in the fluid/wbich should be above $5 \mathrm{mg} / \mathrm{ml}$ of hydatid cyc $\mathrm{Ill}$. Gati $\%$ et al. (1990) estimated the protein content or did and observed the protein content ran ed fron 16 to $20 \mathrm{mg} / \mathrm{ml}$ of the fluid, whereas in the cun $\mathrm{nt}$ study the protein content was 14 and $9 \mathrm{mg} / \mathrm{ml}$ of dialysed tile hydatid cyst fluid respectively, in sheep nd buffalo hydatid cysts.

Craig a Nels on (1984) utilized ELISA and reported the 0 be $\%$ sensitive, the results in the present study 5 cir the earlier report. Similarly, Moosa and Aba Hafez (1994) reported circulating antigen detection using $\mathrm{b}, \mathrm{LISA}$, also decreased the number of false negatives and was more sensitive. The differences in the sensitivity and specificity of the assay may be attributed to low levels of circulating antigen/immune complexes in natural infection of false negative animals, whereas the false positivity could be due to cross reacting circulating antigens of other metacestodes.

Romia et al. (1992) reported circulating antigen detection to be $86 \%$ sensitive by Dot-EIA and the low sensitivity was attributed to small amounts of circulating antigens and immune complex formation $\mathrm{TH}$ in reased sensitivity and specificity as observed in the seit study could be due to high levels of circu ${ }^{1 / \text { ing antigets }}$ which in turn reduces the number of folse gatives and false positives.

Dot-EIA, owing to its hig er sensilivity and specificity in the present study can' pei ner for diagnosing cystic echinococcosis at fie' le because of its simple procedure and rapid re wherea ELISA requires high end equipments with abo, $\neg$ ry procedures.

\section{Referances}

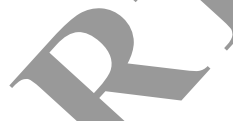

Al Yamai FM, Assaf L, Hailat N, Abdel Hafez FH (1985) Prevalence of hy atidosis in slaughtered animals from North Jordan. Ann Trop Med Parasitol 79:501-506

ig PS, Nelson GS (1984) The detection of circulating antigen in human hydatid disease. Ann Trop Med Parasitol 78:219-227

Caig PS, Rickard MD (1981) Studies on the specific immunodiagnosis of larval cestode infections of cattle and sheep using antigens purified by affinity chromatography in an enzyme linked immunosorbent assay (ELISA). Int $\mathrm{J}$ Parasitol $11: 441-449$

El-Muhtaseb HH (1984) Surgical management of hydatid cysts of the liver: retrospective study of 75 cases. Jordan Med J 18:35-46

Gatne ML, Narasapur VS, Deshpande VS, Niphadkar SM (1990) Protein content and electrophoretic patterns of hydatid fluid. Indian Vet J 67:169-170

Judson DG, Dixon JB, Clarkson MJ, Pritchard J (1985) Ovine hydatidosis: some immunological characteristics of the seronegative host. Parasitology 91:349-357

Lowry OH, Rosebrough NJ, Farr AL, Randall RJ (1951) Protein determination using Folin-Ciocalteu reagent. J Biol Chem 193:265-275

Moosa RA, Abdel Hafez SK (1994) Serodiagnosis and sero epidemiology of human unilocular hydatidosis in Jordan. Parasitol Res 80:664-671

Romia SA, Yousuf ME, Handoussa AE, Rizk HM, Sallam SM (1992) Dot-ELISA as a diagnostic test in hydatid disease. J Egypt Soc Parasitol 22:603-610

Schantz PM (1972) Hydatidosis: magnitude del problemyt perspectivase de control. Biol Sanit-Panam 74:187-197 [Schwabe, C.W.1986. Current issues of hydatid disease: a zoonosis of increasing importance in R.C.A. Thompson] The Biology of Echinococcus and hydatid disease. George Allen and Unwin, London, pp. 81-113. 